\title{
The Composite Materials for Localization of Volatile Radioactive lodine Forms from Steam- Air Phase during Severe Accidents at NPPs
}

\author{
Sergey A. Kulyukhin, Lubov' V. Mizina, \\ Igor' A. Rumer and Nikolay B. Mikheev \\ A.N.Frumkin Institute of Physical Chemistry and Electrochemistry \\ Russian Academy of Sciences \\ Russia
}

\section{Introduction}

The safety of NPPs is currently a problem of particular concern in all industrially developed countries throughout the world. The various science and technology projects being developed in this area seek to minimize the possibility of accidents. During severe accidents the formation of large quantities of gaseous products, which leads to an abrupt increase in pressure inside the containment (protective casing) take place. Eventually, there is a risk of destroying the containment as such. Besides, such accidents may cause contamination of the nuclear power plant closed areas, such as the intercontainment area, technical and service corridors, reactor area, et cetera, due to leakage through non-airtight sectors of the containment. It was established that such a leak of the air-and-steam mix out of the containment can reach a rate of 0.3 to $1.0 \%$ per $24 \mathrm{~h}$. Today, in order to prevent environmental pollution in the event of severe accidents, the operational nuclear power plants are equipped with emergency valves that can be activated to reduce the pressure inside the containment, in which case the air-and-steam flow, carrying radioactive aerosols and volatile fission products, is forced through special decontamination systems (Asmolov, 1994; Particulate Filtration in Nuclear Facilities, 1991; Containment Systems and Components for LOCA and Severe Accident Mitigation, 1993; Rogers, 1990). The all systems, excepting sand bed and gravel filter, have a high efficiency of localization of aerosols, and some of them have a high efficiency relative to molecular form of iodine. However, these systems, excepting Germany system, including the filter based on molecular sieve, practically do not localize the organic form of iodine, such as methyl iodide.

WWER-440/V-230 NPPs are first-generation Russian NPPs that have been operated for more than 25 years now. As the engineering of the designs of these stations was realized long before severe accidents at Three Mile Island and Chernobyl NPPs, all system of localization of accidents was plotted on the concept of impossibility of severe accidents at NPPs. However now point of view varies and the concept of improvement of a protection system of Russian WWER-440/V-230 NPPs with allowance for possibilities of severe accidents is now considered. All modifications of Russian WWER-440/V-230 NPPs belong to this first generation (Kovalevich et al., 2000; Dragunov et al., 2006). 
Modern designs of new generation NPPs (EPR / Framatome ANP/, SWR-1000 /Framatome ANP/, AP-1000 /Westinghouse/, ESBWR /General Electric/, APWR /Mitsubishi/, ABWR /Toshiba and Hitachi/) do not provide for pressure-drop systems, assuming that the entire peak load will be withheld by the containment (Reactor Design, 2002; Krebs, 1999; Tomorrow's reactors, 2003). Calculations show that during $122 \mathrm{~h}$, pressure under the containment can raise up to $0.7 \mathrm{MPa}$, with the steam/air ratio being 2.7:1 (Dillman, 1991). This time is enough for the steam-air joint containing volatile radioactive fission products to penetrate ( 0.3 to $3 \%$ per day) into the intercontainment area and then into the environment. To prevent radioactive contamination of the environment, modern designs propose using an active air decontamination system, which using high-capacity ventilators, will forward the air from the intercontainment area to filters filled with impregnated activated charcoal. This system requires regular electric power supply, which is a significant disadvantage of this technological approach.

However, in accordance with the general requirements for safety systems, alongside active ventilation systems for intercontainment space, nuclear power plants should include a passive ventilation system, which can be used during hypothetical severe accident with a complete loss of power supply.

Now a passive-mode environmental protection system for decontamination of intercontainment area, which can be used in the event of severe accidents, was developed (Bronnikov, 2004; Zeyen et al., 2006; Friesen et al., 2001; Asmolov, 1994; Kulyukhin et al., 2008; State of the art report on iodine chemistry, 2007; State of the art report on nuclear aerosols, 2009; Kulyukhin et al., 2011). The basic purpose of developed passive filtration system is creation of a rarefaction in an intercontainment space due to the organized removal of the radioactive steam-air mixture from an intercontainment space at full loss of all power sources. Steam-air mixture containing radioactive aerosols and flying fission products removal from an intercontainment space is passed through the special filtering module. Efficiency of cleaning of a radioactive steam-air mixture is determined by filtration and sorption properties of used filtering elements.

One of the nuclear fuel fission products of high environmental emergency is radioactive iodine. The International Atomic Energy Agency (IAEA) classifies accidents and other events occurring at nuclear industry enterprises in terms of the amount of radioiodine release into the environment (Bukrinskii et al., 1991). Currently we know about the existence of 14 iodine nuclides, of which only ${ }^{127}$ is stable. Given an average nuclear fuel burn up depth of $45 \mathrm{GWd} / \mathrm{t}$, one ton of irradiated nuclear fuel of PWR type (in Russia, WWER) contains $200 \mathrm{~g}$ to $300 \mathrm{~g}$ of iodine radionuclides or about $12 \mathrm{~kg}$ per the entire amount of fuel in the reactor (Radioiodine Removal in Nuclear Facilities, 1980; Ustinov et al., 2005). During a long exposure of fuel elements, all short-lived iodine radionuclides decompose, and as a result the irradiated nuclear fuel that goes to reprocessing plants includes either two (127I, $\left.{ }^{129} \mathrm{I}\right)$ or three (127I, 129I, 131I) iodine nuclides, depending on the time of storage.

On the other hand, a totally different situation may occur during accidents at nuclear power plants and especially during non-design accidents associated with nuclear fuel melting. Depending on the length of the event, the amount of radioiodine in the fuel that fully penetrates into the primary containment environment and further, possibly, into the open environment may vary from hundreds of grams to tens of kilograms. To predict the chemical forms of radioiodine and their concentrations in the containment environment during non-design accidents, the Library of Iodine Reactions in Containment (LIRIC) was created. It includes over 150 chemical reactions of iodine, including those with organic 
species (Evans et al., 1990). The variety of the chemical forms of radioactive iodine in gaseous media needs sophisticated protective system to localize it during irradiated nuclear fuel reprocessing, as well as in the protective systems at nuclear power plants (Particulate Filtration in Nuclear Facilities, 1991). Despite a great number of volatile forms of radioiodine, the focus of attention in modern irradiated nuclear fuel reprocessing systems in both Russia and abroad, as well as at all nuclear power plants, is the localization of CsI radioactive aerosols and gaseous $\mathrm{I}_{2}, \mathrm{HI}$, and $\mathrm{CH}_{3} \mathrm{I}$.

The study of the sorption of volatile compounds of radioactive iodine from a gas phase on a wide spectrum of sorbents has shown that the most effective are the sorbents containing 8-12 wt $\%$ of Ag (Kulyukhin et al., 2008; State of the art report on iodine chemistry, 2007; Kulyukhin et al., 2011). Because of high cost of Ag, which is the one of the basic components connecting radioactive iodine, there is a problem of decreasing of its quantity in sorbents by their modifying, or makes topical its replacement. Apparently, the most suitable for this purpose are $d$-elements whose physicochemical properties are close to those of $\mathrm{Ag}$, namely, $\mathrm{Cu}, \mathrm{Ni}$ and $\mathrm{Zn}$. The aim of this study was to develop new composites based on $\mathrm{Ag}-, \mathrm{Ni}-, \mathrm{Zn}$ - and $\mathrm{Cu}-$ containing silica gel for localization of volatile compounds of radioactive iodine from steamair phases. These composites will be used during modernization of the environmental protection systems during severe accidents at the different types of NPPs.

\section{Experimental}

In our study we used the radionuclide ${ }^{131}$ I supplied by Izotop Joint-Stock Company in the form of carrier free $\mathrm{Na}^{131}$ I solution. The radioactivity of the nuclides was determined by $\gamma^{-}$ ray spectrometry with a semiconductor Ge-Li detector on a multichannel analyzer. The radionuclide ${ }^{131}$ I was used as this study as a spike for weighable amount of inactive iodine. Therefore, designations like ${ }^{131} \mathrm{I}_{2}$ and $\mathrm{CH}_{3}{ }^{131}$ I refer to labeled species and not to species of pure ${ }^{131} \mathrm{I}$ radionuclide.

We used ${ }^{131} \mathrm{I}_{2}(10-100 \mathrm{mg})$ and also $\mathrm{CH}_{3}{ }^{131} \mathrm{I}(1-10 \mathrm{mg})$ with the specific activity from $3 \times 10^{2}$ to $3 \times 10^{3} \mathrm{~Bq} / \mathrm{mg}$. The ${ }^{131} \mathrm{I}_{2}$ generated in a gas phase by bubbling of water solution $\mathrm{K}^{131} \mathrm{I}_{-1}{ }^{131} \mathrm{I}_{2}$ by a steam-air flow. As a collector of $\mathrm{CH}_{3} \mathrm{I}$ labeled with 131I we used a quartz vessel into which, prior to experiment, we condensed with liquid nitrogen from a helium flow 1-100 $\mathrm{mg}$ of $\mathrm{CH}_{3}{ }^{131} \mathrm{I}$ prepared by the reaction of dimethyl sulfate with $\mathrm{K}^{131} \mathrm{I}$ (Murata et al., 1968).

In the experiment, methyl iodide was introduced into the system by passing air at a definite rate through the quartz vessel with $\mathrm{CH}_{3}{ }^{131} \mathrm{I}$.

To prepare composites, we used macroporous silica gel with a particle size of $2.00-3.00 \mathrm{~mm}$ as matrices.

Nitrates of $\mathrm{Zn}^{2+}, \mathrm{Cu}^{2+}, \mathrm{Ni}^{2+}$, and $\mathrm{Ag}^{+}$, and also all the acids, alkalis and hydrazine hydrate $(\mathrm{HH})$ used in the study were of chemically pure grade. Pure grade hydroxylamine sulfate (HA) was used without additional purification.

Mechanical strength of granules of developed composites was measured on MP-2C device. Electron micrographs of developed composites were obtained on the electron microscope TEM-301 ("Philips").

X-ray electron probe microanalysis (EPM) of developed composites was made on the scanning electron microscope JSM-U3 (Japan) with energy dispersive spectrometer "Eumex" (Germany).

Thermal gravimetric analysis of developed composites was performed with a Q-1500 derivatograph (MOM, Budapest, Hungary). Samples were heated in platinum crucibles in air at a rate of $10 \mathrm{deg} / \mathrm{min}$. 


\subsection{Ag-containing composites}

\subsubsection{Synthesis of Ag-containing composites}

The composites containing 1-8 wt\% of $\mathrm{AgNO}_{3}$ were prepared by impregnation with an aqueous solution of $\mathrm{AgNO}_{3}$ with the following treatment by different $\mathrm{N}$-containing compounds with the following drying on air at increasing of temperature from 20 to $300^{\circ} \mathrm{C}$ and next air-conditioning at $300^{\circ} \mathrm{C}$.

Composites were synthesized in two stages:

1. Impregnation of macroporous silica gel with a solution of $\mathrm{AgNO}_{3}$ with the following drying on air at $110^{\circ} \mathrm{C}$;

2. Treatment of precursors with solutions of N-containing compounds with the following drying on air at increasing of temperature from 20 to $300^{\circ} \mathrm{C}$ and next air-conditioning at $300^{\circ} \mathrm{C}$ during $4 \mathrm{~h}$.

The quantity of a solution of the $\mathrm{AgNO}_{3}$, which is necessary for impregnation of silica gel, was taken in an amount ensuring $50 \%$ filling of the volume of the silica gels. The volume of silica gel was calculated from its bulk weight, which equal $0.576 \mathrm{~kg} / \mathrm{m}^{3}$.

The quantity of $\mathrm{AgNO}_{3}$ for synthesis of composites was calculated on the basis of data about necessary Ag concentration in precursor.

The first stage of synthesis of precursors of composites on a basis of macroporous silica gel containing Ag was carried out as follows. At intensive mixing a $434 \mathrm{~cm}^{3}$ of a solution of $\mathrm{AgNO}_{3}$ with necessary concentration was added to $500 \mathrm{~g}$ of macroporous silica gel. The obtained mixture was mixed during $60 \mathrm{~min}$ for obtaining of uniformity of impregnation of total joint of silica gel with solution of $\mathrm{AgNO}_{3}$.

After obtaining of proportional impregnation of total joint of silica gel with solution of $\mathrm{AgNO}_{3}$ the wet sample was placed in BINDER drier. Precursors were dried on air at temperature $110^{\circ} \mathrm{C}$ to an air-dry state.

As a result of these operations there was a partial destruction of granules of precursor. Therefore before carrying out of the second stage of synthesis of composites it has been made the fractioning. As result of the fractioning of precursor granules with the size less than $1 \mathrm{~mm}$ has been separated. The quantity of the given fraction did not exceed $2-3 \%$ from total synthesized joint of precursor.

As a result the precursors, containing 1,2, 4 and $8 \mathrm{wt} \%$ of $\mathrm{Ag}$ on the basis of macroporous silica gel, were synthesized.

At the second stage of synthesis of composites the precursors were treated by different $\mathrm{N}$ containing compounds with the following drying on air at increasing of temperature from 20 to $300^{\circ} \mathrm{C}$ and next air-conditioning at $300^{\circ} \mathrm{C}$ during $4 \mathrm{~h}$.

In our study $0.01,0.05$ and $0.1 \mathrm{M}$ water solutions of $\mathrm{HH}$ and $\mathrm{HA}$, and $0.5,1.0$ and $2.0 \mathrm{M}$ water solutions of $\mathrm{NH}_{4} \mathrm{OH}$ were used as $\mathrm{N}$-containing compounds.

The second stage consists on treatment of precursor by $\mathrm{N}$-containing compounds for obtaining of composites with nanometric particles of different compounds of $\mathrm{Ag}$, was carried out as follows. At intensive mixing the $80 \mathrm{~cm}^{3}$ of solution of $\mathrm{N}$-containing compound with necessary concentration were added to $100 \mathrm{~g}$ air-dry precursor, containing 1, 2, 4 or 8 $\mathrm{wt} \%$ of $\mathrm{AgNO}_{3}$. The obtained mixture was mixed during $60 \mathrm{~min}$ for obtaining of uniformity of impregnation of joint of precursor with solution of $\mathrm{N}$-containing compounds. During impregnation the colour of precursor changed from white to grey.

After obtaining of proportionality of impregnation of total joint of precursor that proved to be true of uniformity of colour, the wet samples were placed in exiccator on $3 \mathrm{~h}$. Through $3 \mathrm{~h}$ wet samples were placed in BINDER drier. The wet samples of composites were dried on air 
at increasing of temperature from 20 to $275-300^{\circ} \mathrm{C}$ with the following air-conditioning during $4 \mathrm{~h}$ at temperature $275-300^{\circ} \mathrm{C}$.

As a result of these operations the composites, containing 1, 2, 4 and $8 \mathrm{wt} \%$ of nanometric particles of different compounds of $\mathrm{Ag}$, on a basis of macroporous silica gel were obtained.

As above mentioned, during treatment of precursors by N-containing compound its colours changed. Besides, the change of precursor's colour, containing $\mathrm{AgNO}_{3}$, was observed at long-term exposure on them of sunlight. The change of colour is connected with photo reduction of ions of $\mathrm{Ag}$ to a metal state on the surface of material.

\subsubsection{The content of $\mathrm{Ag}$ in synthesized composites}

Percentage content of Ag in synthesized precursors and composites is specified by quantity of $\mathrm{AgNO}_{3}$, which was used for impregnation of macroporous silica gel. Whereas during synthesis of precursors and its modifying it is possible the loss of Ag with dust fraction, the final content of $\mathrm{Ag}$ in precursors and composites is determined by an analytical method by the following technique. The joint of precursor or composite $(\sim 1 \mathrm{~g})$ carefully triturate in a porcelain mortar in the presence of $10 \mathrm{~cm}^{3}$ of water. Suspension quantitatively transfers in $30-\mathrm{cm}^{3}$ centrifuge tube and $10 \mathrm{~cm}^{3}$ of concentrated $\mathrm{HNO}_{3}$ was added to suspension. Than centrifuge tube with suspension was heated up during $1 \mathrm{~h}$ on a boiling water bath. After heating centrifuge tube was cooled and a solution was separated from solid phase by centrifugation. The solid phase was washed 3 times by $25 \mathrm{~cm}^{3}$ of distilled water. The solution and all washings were merged in $100-\mathrm{cm}^{3}$ volumetric flask for titration. The solution in volumetric flask was reduced to $100 \mathrm{~cm}^{3}$ and than the determination of $\mathrm{Ag}$ by titration on Volgard's method from $0.01 \mathrm{~N}$ solution of $\mathrm{NH}_{4} \mathrm{SCN}$ at presence of iron ammonium alum indicator was carried out (Charlout, 1961). The content of Ag was calculated by the formula:

$$
\% \mathrm{Ag}=\left(\mathrm{N}_{1} \times \mathrm{V}_{1} \times \mathrm{M}\right) /\left(\mathrm{V}_{2} \times \mathrm{P}\right),(1)
$$

where $N_{1}$ - normality of $\mathrm{NH}_{4} \mathrm{SCN}$ solution; $V_{1}$ - volume of $\mathrm{NH}_{4} \mathrm{SCN}$ solution, which was used for titration, $\mathrm{cm}^{3} ; V_{2}$ - aliquot of $\mathrm{Ag}$ solution for analysis, $\mathrm{cm}^{3} ; M$ - gramm-equivalent of Ag; $P$ - joint of composite, $g$.

The analysis of data on the Ag content in synthesized precursors and composites shows that the content of $\mathrm{Ag}$ in synthesized composites is in the range from 1.0 to $8.0 \mathrm{wt} \%$ that is from 95 to $99.9 \%$ from Ag quantity taken for synthesis.

\subsubsection{Desorption of $\mathrm{Ag}$ from synthesized composites into water}

During treatment of precursors by $\mathrm{N}$-containing compounds the poorly soluble compounds of $\mathrm{Ag}$ in the composites are formed. At treatment of precursors by $\mathrm{HH}$ and $\mathrm{HA}$ the $\mathrm{Ag} 0$ particles can be formed. At treatment of precursors by $\mathrm{NH}_{4} \mathrm{OH}$ both $\mathrm{Ag}_{2} \mathrm{O}$ and $\mathrm{Ag}^{0}$ particles can be formed. For study of degree of conversion of $\mathrm{AgNO}_{3}$ to poorly soluble compounds studies of Ag desorption from synthesized precursors and composites into water were carried out.

The study of Ag desorption from composites into water was carried out as follows. The joint of composite $(\sim 1 \mathrm{~g})$ carefully triturate in a porcelain mortar in the presence of $10 \mathrm{~cm}^{3}$ of water. Suspension quantitatively transfers in $30-\mathrm{cm}^{3}$ centrifuge tube. The suspension was conditioned on $24 \mathrm{~h}$ at temperature $18-20^{\circ} \mathrm{C}$. After that a solution was separated from solid phase by centrifugation. The solid phase was washed 3 times by $25 \mathrm{~cm}^{3}$ of distilled water. 
The solution and all washings were merged in $100-\mathrm{cm}^{3}$ volumetric flask for titration. The solution in volumetric flask was reduced to $100 \mathrm{~cm}^{3}$ and than the determination of $\mathrm{Ag}$ by titration on Volgard's method from $0.01 \mathrm{~N}$ solution of $\mathrm{NH}_{4} \mathrm{SCN}$ at presence indicator iron ammonium alum was carried out (Charlout, 1961). The content of Ag was calculated by the formula (1).

Analysis of data on the desorption of $\mathrm{Ag}$ from synthesized composite into water for $24 \mathrm{~h}$ at temperature $18-20^{\circ} \mathrm{C}$ shows that the quantity of $\mathrm{Ag}$ which has passed into water from synthesized composites does not exceed 18\% from total quantity of Ag in composites.

\subsubsection{Fractional content of synthesized composites.}

Determination of fractional content of synthesized composites was carried out using a nest of sieves (hole diameters were from 7.0 to $0.3 \mathrm{~mm}$ ) by shaking of 200-400 $\mathrm{g}$ of composite for $15 \mathrm{~min}$ in according with technique, presented in (State Standard 16187-70, 1970). The resultant separated fractions were weighted. The percentage of each fraction was calculated by the formula:

$$
\%=(\mathrm{m} / \mathrm{M}) \times 100,(2)
$$

where $\mathrm{m}$ - weight of separated fraction, $\mathrm{g} ; \mathrm{M}$ - total weight of composite taken for the analysis, $\mathrm{g}$.

Analysis of data on the fractional content of averaged sample of synthesized composites shows that during synthesis the composites practically have not changed its initial fractional content. The changes of basis fraction of macroporous silica gel with the size of granules from 2.0 to $3.0 \mathrm{~mm}$ were not more than $2 \%$.

\subsubsection{Free volume of synthesized composites}

The free volume, which is a sum of pore volumes of composite and intergranule space, was determined in the following way. $10 \mathrm{~cm}^{3}$ of hexane was added to $5 \mathrm{~g}$ of air-dry composite. Suspension carefully was mixed before full removal of air bubbles and than was conditioned during $24 \mathrm{~h}$ at temperature $20^{\circ} \mathrm{C}$. Through $24 \mathrm{~h}$ summary volume of composite and hexane was measured. Knowing volume of air-dry composite, the free volume of composite $\mathrm{V}_{\text {free }}$ was calculated by the formula:

$$
\mathrm{V}_{\text {free }}=\left\{\left[\left(\mathrm{V}_{1}+\mathrm{V}_{2}\right)-\mathrm{V}_{3}\right] / \mathrm{V}_{1}\right\} \times 100 \%,(3)
$$

where $\mathrm{V}_{1}$ - volume of a joint of air-dry composite, $\mathrm{cm}^{3} ; \mathrm{V}_{2}$ - volume of hexane, $\mathrm{cm}^{3} ; \mathrm{V}_{3}$ - final volume of composite and hexane through $24 \mathrm{~h}, \mathrm{~cm}^{3}$.

Analysis of data on free volume of composites shows that the free volumes for synthesized composites were in the range from 72 to $80 \%$. The obtained data on free volume of material allow concluding that synthesized composites have large specific surface and total volume of pores. The extended surface and large porosity of composites suggests both high rate of sorption of volatile compounds, and low aerodynamic resistance to a gas flow.

\subsubsection{Bulk weight of synthesized composites}

Bulk weight of composites was determined as the ratio of mass of an air-dry material and the volume taken by it. Analysis of data on bulk weight of synthesized composites shows that synthesized composites have bulk weights from 0.5 to $0.7 \mathrm{~g} / \mathrm{cm}^{3}$ or $500-700 \mathrm{~kg} / \mathrm{m}^{3}$. The sufficiently low density of synthesized composites, as well as high values of free volume, indicates to large porosity of composites and, hence, a well developed specific surface. 


\subsubsection{Mechanical strength of synthesized precursors and composites}

Mechanical strength of granules of precursors and composite was measured on MT-2C device which scheme is presented on Fig. 1. The device was developed and designed in Institute of Physical Chemistry and Electrochemistry of Russian Academy of Sciences. The principle of operation of this device consists in loading the sample at constant speed of a working table movement and fixing the breaking force on the indicating gage. Mechanical strength $\sigma_{\mathrm{p}}$ was calculated by the formula:

$$
\sigma_{\mathrm{p}}=4 \mathrm{P} / \pi \mathrm{d}^{2},(4)
$$

where $\mathrm{P}$ - the load $(\mathrm{kg}), \mathrm{d}$ - the diameter of granules of materials under study $(\mathrm{cm})$.

Samples of composites were a mixture of different particles (mall, hemispherical and spherical). Only spherical granules (12 samples) with an average diameter $3.0 \mathrm{~mm}$ were used for measurement of mechanical strength $\sigma_{\mathrm{p}}$. The granules were tested on squeeze in static conditions on MT-2C device at loading rate $1 \mathrm{~mm} / \mathrm{min}$. During measurements mechanical strength of granules $\sigma_{\mathrm{p}}\left(\mathrm{kg} / \mathrm{cm}^{2}\right)$ and a roof-mean-square deviation $S_{n \bar{x}}$ from arithmetical mean $S_{n}$ for 36 samples were determined.

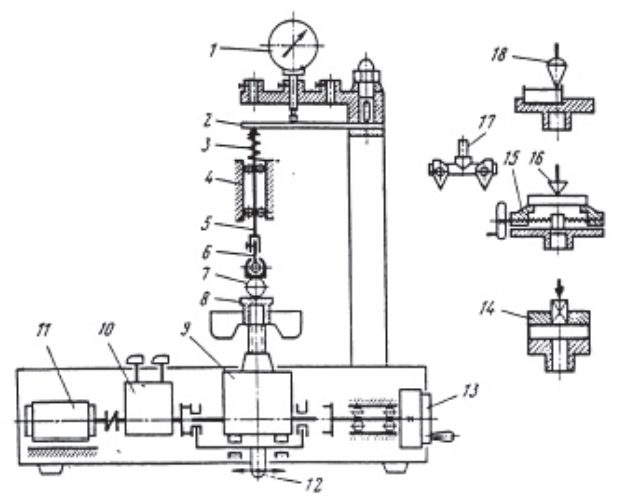

Fig. 1. The scheme of MT-2C device (1 - indicator of displacements, 2 - a flat spring of weighting device, 3 - a spring for rod weighing, 4 - guide ways, 5 - a rod, 6 - the top support, 7 - the sample, 8 - a working little table, 9 - a reduction unit, 10 - a speed gear box, 11 electric motor, 12 - the shifter of the electric motor or handcrank to a reduction unit, 13 - a handcrank, 14 - the adaptation for test of samples for a cut, 15 - a movable support for test of samples for a bending under $3^{\text {th }}$ and $4^{\text {th }}$ dot scheme, 16 - a prism, 17 - a movable wedge for test of samples for a bending under $4^{\text {th }}$ dot scheme, 18 - a cone with various corners for test of pastes on a method conical plastometer)

Analysis of results of tests of 36 samples of granules of composites under static loading shows that strength of granules increases with an increase in the quantity of Ag in material, i.e., the structure of the materials strengthens. On the other hand, strength of granules of composites was lower than strength of analogous precursors. Decreasing of mechanical strength occurs as a result of changing of structure of macroporous silica gel during treatment of precursors by N-containing compounds. It is known, that during treatment of silica gel by alkaline solutions dissolution of gel silica acid, which are in a pores of silica gel, takes place. The similarly process of dissolution of gel silica acid in pores of silica gel 
occurred during treatment of precursors by $\mathrm{N}$-containing compounds. Besides, during treatment of precursors by $\mathrm{N}$-containing compounds there was a change of the chemical forms of $\mathrm{Ag}$ in the materials under study. As a result of the various physico-chemical processes, which occurred in granules of material, there was an increasing of pore volumes of granules that leads to decrease in mechanical strength of granules. Mechanical strength of composites was more than $85 \mathrm{~kg} / \mathrm{cm}^{2}$.

\subsubsection{Electron microscopy study of synthesized composites}

Figure 2 show the electron micrographs of the synthesized composites $\mathrm{SiO}_{2}-\mathrm{n} \% \mathrm{Ag}(\mathrm{n}=1,8)$, obtained using a Philips TEM-301 transmission electron microscope. As shown in Fig. 2, the synthesized materials contain $\mathrm{Ag}^{0}$ nanometer particles not larger than $10 \mathrm{~nm}$. The amount of the nanometer particles increases with an increase in the Ag concentration in the materials. Note that the amount of $\mathrm{Ag}^{0}$ nanometer particles depends not only on the Ag concentration in the material, but also on the nature of the nitrogen-containing compound used for the modification of the precursor.

A study of the microphotographs showed that the largest particles were formed during treatment of the precursor with ammonia solutions. The particles form aggregates (Fig. 2B). When $\mathrm{HH}$ or HA is used, highly dispersed particles stabilized in the matrix pores are formed (Fig. 2A). On the hand, decreasing the Ag concentration during treatment of the precursor with ammonia solutions leads to the formation of highly dispersed particles in the silica gel matrix (Fig. 2B).

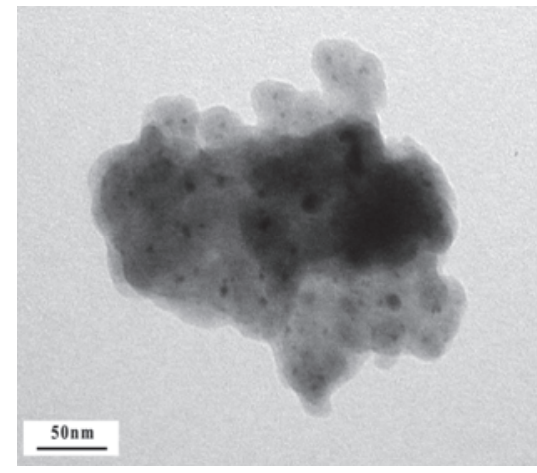

A

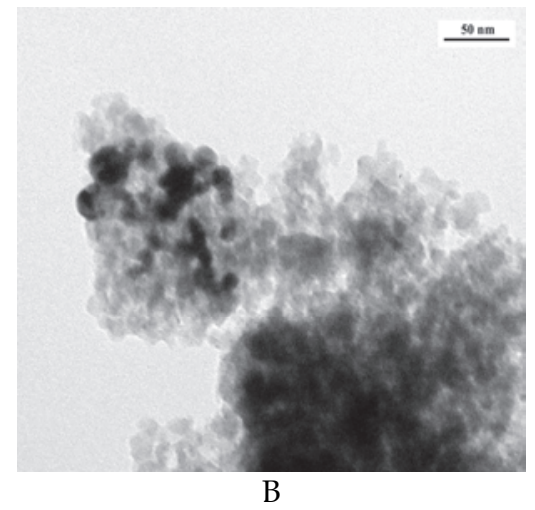

B

Fig. 2. The electron microphotograph of the composite $\mathrm{SiO}_{2}-8 \% \mathrm{Ag}$ obtained by treatment of the precursor with solutions of $0.1 \mathrm{M} \mathrm{HH}(\mathrm{A})$ and $0.5 \mathrm{M} \mathrm{NH}_{4} \mathrm{OH}$ (B)

As follows from Fig. 2, the amount of nanometer $\mathrm{Ag}^{0}$ particles is very small, which, as we believe, indicates the formation in the matrix of $\mathrm{Ag}$ particles smaller of a size smaller than the equipment resolution power, i.e., $<1 \mathrm{~nm}$. In addition, it is necessary to take into account a low concentration of $\mathrm{Ag}$ in the matrix of the composite with a strongly developed surface. The Ag distribution in the matrix of the composites was studied using their electron probe $X$-ray microanalysis. Figure 3 shows a typical microphotograph of the surface of the chip of the granule of the composite, and fig. 4 shows the X-ray diffraction spectrum of the sample surface. As follows from Figure 3, particles not larger than $1 \mu \mathrm{m}$ are evenly distributed on the granule surface and that the amount of the aggregates larger than $10 \mu \mathrm{m}$ is relatively 
small. An elemental composition study of the surface showed that the composites contained O, Si, and Ag (Fig. 4).

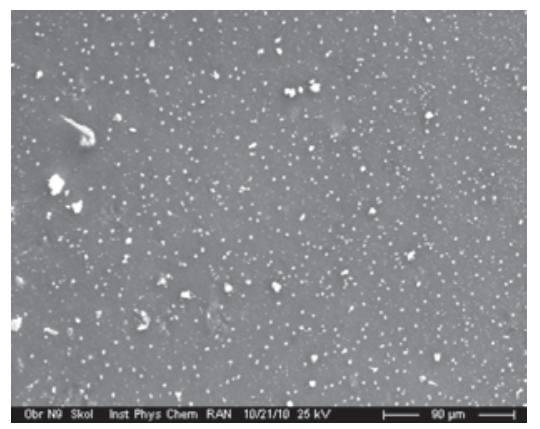

Fig. 3. The microphotograph of the surface of the $\mathrm{SiO}_{2}-4 \% \mathrm{Ag}$ composite

Figure 5 shows the X-ray spectroscopy data on the Ag distribution on the surface of granules of $\mathrm{SiO}_{2}-\mathrm{n} \% \mathrm{Ag}(\mathrm{n}=1,2,4,8)$ composites after treatment of the precursors with solutions of $\mathrm{HH}$ and HA. The surface of the granules was scanned at a radiation power only characteristic of Ag.

As follows from fig. 5, the Ag particles are virtually evenly distributed on the surface of the composite granules. The amount of the particles on the surface decreases with a decrease in the Ag concentration.

The obtained results are good agreement with the conclusions drawn from the microphotographs obtained using transmission electron microscopy. Actually, the welldeveloped surface of the synthesized composites stimulates a strong distribution of $\mathrm{Ag}$ in the volume of the granules of the material. As a result, when the Ag concentrations are low, the number of $\mathrm{Ag}$ particles per surface unit of the material proves to be very low.

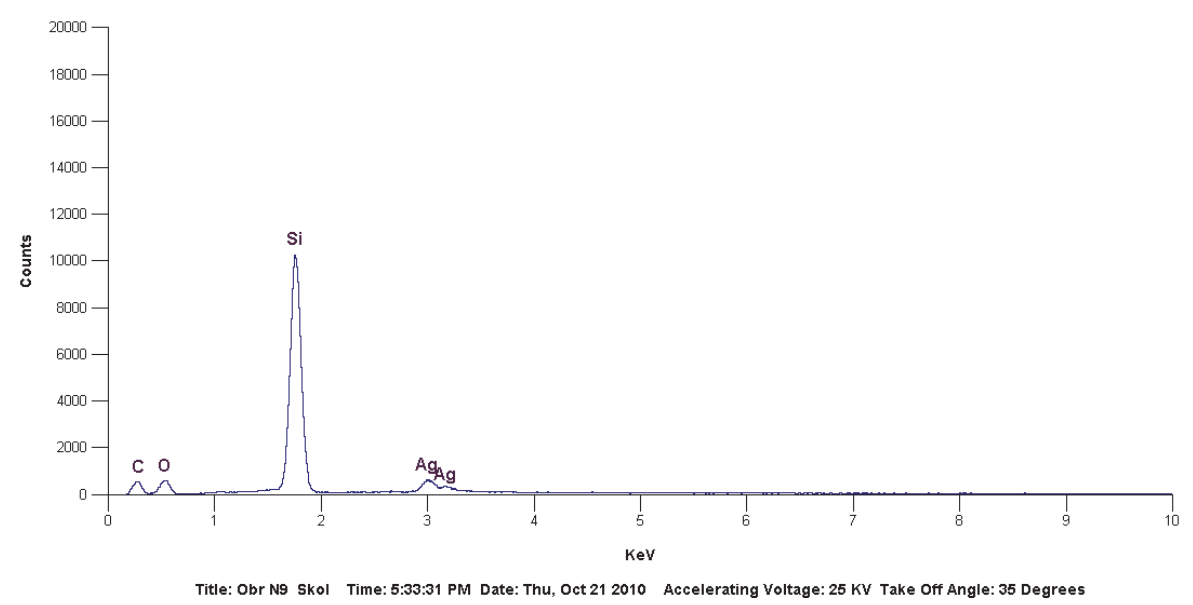

Fig. 4. The X-ray diffraction spectrum of the $\mathrm{SiO}_{2}-4 \% \mathrm{Ag}$ composite after treatment of the precursors with solutions of $\mathrm{HH}$ 


\subsubsection{Localization of molecular iodine and methyl iodide from a steam-air flow}

The efficiency of molecular iodine and methyl iodide localization by composites under analogous experimental conditions depends on many factors, the main of which are as follows: active metal concentration, preparation conditions, quantity of methyl iodide or molecular iodine, steam-air flow rate, and time of contact between the steam-air flow and the composite.

\subsubsection{A study of the localization of molecular radioiodine from a steam-air flow}

To study the localization of ${ }^{131} \mathrm{I}_{2}$ from a steam-air flow, we used the procedure and installation described in (Kulyukhin et al., 2007).

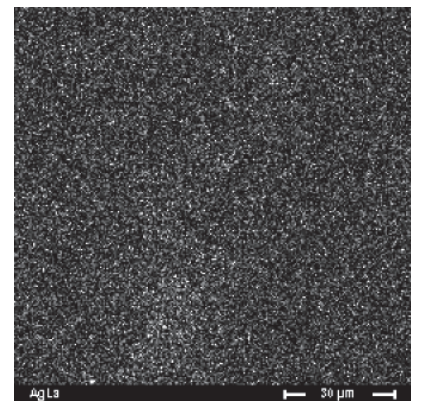

A

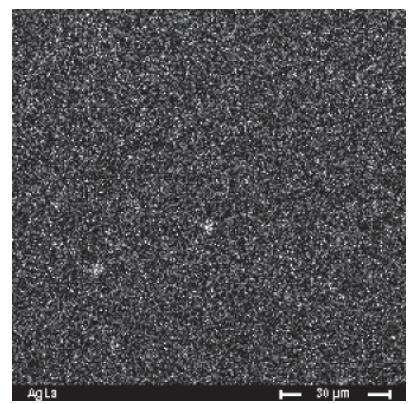

B

Fig. 5. The distribution of Ag particles on the surface of the granule of the composite based on silica gel containing $4 \mathrm{wt} \% \mathrm{Ag}(\mathrm{A})$ and $8 \mathrm{wt} \% \mathrm{Ag}(\mathrm{b})$ after treatment of the precursor with a $0.1 \mathrm{M}$ solution of $\mathrm{HH}$ and conditioning in the air at $300^{\circ} \mathrm{C}$ for 4 hours

It is necessary note that the efficiency of molecular iodine absorption is higher than $99 \%$ virtually in all cases. After the localization of molecular iodine, the composite changed its color from grey to lettuce green. The appearance of the lettuce green color is due to the formation of $\mathrm{Ag}^{131} \mathrm{I}$ in the composition of the composite.

Note that irrespective of the Ag concentration in the composite, the absorption efficiency is the highest in the case of using HA and is the lowest in the case of using the ammonia solution (Fig. 6). The composites obtained by treatment with $\mathrm{HH}$ take an intermediate position. The observed difference is most likely due to the formation of metal Ag particles in the case of $\mathrm{HH}$ and $\mathrm{HA}$ versus the formation of Ag oxide in the case of using ammonia solutions. Note that treatment of HA leads to the formation of smaller particles versus $\mathrm{HH}$.

As follows from Fig. 6, when the Ag concentration in the material is increased from 1 to 8 $\mathrm{wt} \%$, the total molecular iodine sorption by the total layer of the sorbent remains virtually unchanged and higher than $99 \%$. Despite the virtually equal sorption efficiencies, different distributions of molecular iodine in the layers of the column are observed. Analysis of the layer-by-layer distribution of radioactive iodine in the column as a function of the $\mathrm{Ag}$ concentration in the material shows that when the Ag concentration in the material is increased, the sorption front becomes steeper, i.e., the major part of molecular iodine is absorbed in the first layer of the material. The formation of the nanometer Ag particles in the case of $\mathrm{HH}$ and HA results in a high sorption efficiency of the synthesized materials. On the other hand, the formation of nanometer Ag oxide particles in the case of treatment of the precursors with an ammonia solution leads to a lower-angle front of the sorption curves 
along the columns. The difference in the slopes of the sorption curves allows us to draw conclusions regarding not only the possible Ag form in the composite, but also regarding the chemosorption speed for its different forms. For $\mathrm{Ag}$ oxide, the molecular iodine chemosorption rate is about 1.5 times slower than that on the metal Ag particles obtained by treatment of the precursors with $\mathrm{HH}$ or HA.

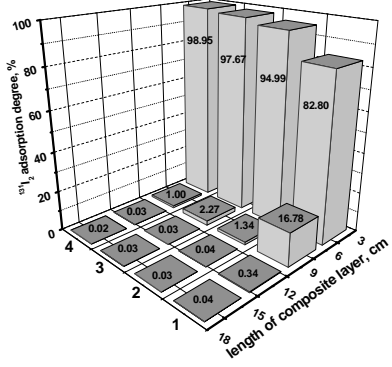

A

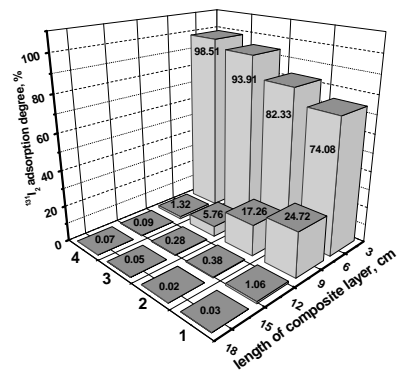

B

Fig. 6. The 131I layer-by-layer distribution on the column with the composite materials obtained by treatment of the precursor with a $0.1 \mathrm{M}$ solution of $\mathrm{HA}(\mathrm{A})$ and $\mathrm{NH}_{4} \mathrm{OH}(\mathrm{B})$ as a function of the Ag concentration in the material (1 - wt $\% \mathrm{Ag}, 2-2 \mathrm{wt} \% \mathrm{Ag}, 3-4 \mathrm{wt} \% \mathrm{Ag}, 4$ $8 \mathrm{wt} \% \mathrm{Ag})$

All synthesized composites display high molecular iodine sorption efficiency. Note that the sorption efficiency of each of the studied materials is virtually independent of the nature of the $\mathrm{N}$-containing compound used for treatment of the precursor.

Analysis of the layer-by-layer distribution of radioactive iodine on the column containing the $\mathrm{SiO}_{2}-2 \% \mathrm{Ag}$ composite obtained by treatment of the precursor by different $\mathrm{N}$-containing compounds shows the layer-by-layer distribution of radioactive iodine along the column filled with the precursor of the given composite (Fig. 7). The lowest-angle molecular iodine sorption front in the layers of the column is observed for the composite obtained by treatment of the precursor with the ammonia solution; the rate of the chemosortion by $\mathrm{Ag}$ oxide particles is the lowest as compared with other Ag forms. The chemosorption speed for the non-modified $\mathrm{Ag}$ form $\left(\mathrm{AgNO}_{3}\right)$ is virtually the same as that on the metal Ag particles obtained by treatment of the precursor with a $0.1 \mathrm{M}$ solution of HA. The highest value is observed for the composite obtained during treatment of the precursor with a $0.1 \mathrm{M}$ solution of $\mathrm{HH}$. During treatment of the precursor with $\mathrm{HH}$, metal Ag particles are formed in the near-to-surface layer of the granules, whereas during treatment with $\mathrm{HA}$, the metal $\mathrm{Ag}$ particles are formed in the entire volume. As a result, gaseous molecular iodine takes a longer time to enter the chemosorption reaction with the Ag particles in the volume of the granules versus its reaction with the Ag particle in the near-to-surface layer or on the surface of the granules. Note that because of the high porosity of the material the difference in the molecular iodine sorption efficiencies in the $1^{\text {st }}$ layer of the sorbents obtained by treatment of the precursor with $\mathrm{HH}$ and $\mathrm{HA}$ is very small.

Figure 8 shows the data on the molecular iodine sorption efficiency on the $\mathrm{SiO}_{2}-2 \% \mathrm{Ag}$ composite obtained by treatment of the precursor with a $0.01 \mathrm{M}$ solution of $\mathrm{HH}$ as a function 
of the molecular iodine quantity supplied to the column. As follows from Fig. 8, when the molecular iodine quantity is increased tenfold (from 10 to $100 \mathrm{mg}$ ), the sorption efficiency remains virtually unchanged and is very high (higher than 99.9\%). On the other hand, increasing the molecular iodine quantity leads to its redistribution in the layers of the column.

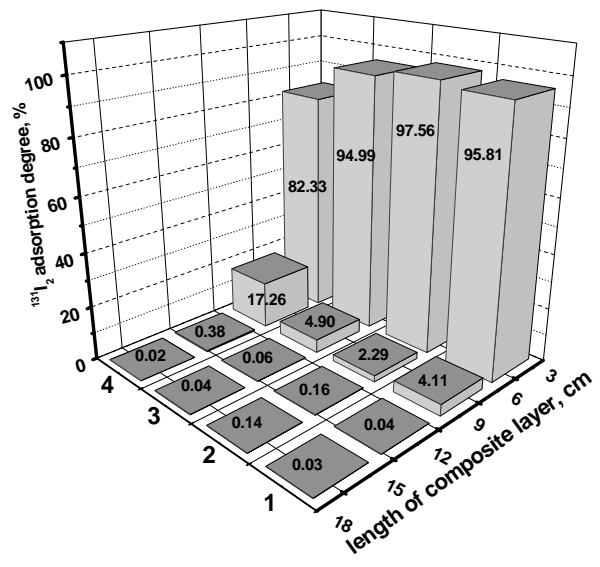

Fig. 7. The ${ }^{131} \mathrm{I}$ layer-by-layer distribution on the column containing the $\mathrm{SiO}_{2}-2 \% \mathrm{Ag}$ composite material as a function of the nature of the $\mathrm{N}$-containing compound used for treatment of the precursor (1 - without modification, 2 - $0.1 \mathrm{M}$ hydrazine hydrate, $3-0.1 \mathrm{M}$ hydroxylamine, 4 - $0.5 \mathrm{M} \mathrm{NH}_{4} \mathrm{OH}$ )

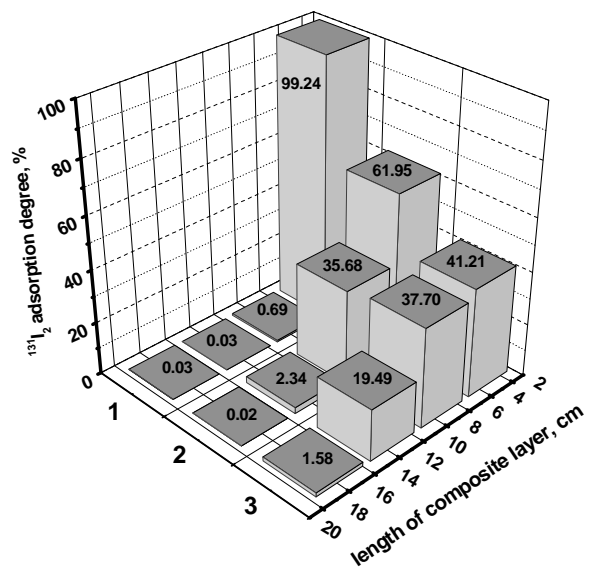

Fig. 8. The ${ }^{131} \mathrm{I}$ layer-by-layer distribution on the column containing the $\mathrm{SiO}_{2}-2 \% \mathrm{Ag}$ composite material obtained by treatment of the precursor with $0.01 \mathrm{M}$ solution of $\mathrm{HH}$ as a function of the ${ }^{131} \mathrm{I}_{2}$ quantity $(1-10 \mathrm{mg}, 2$ - $50 \mathrm{mg}, 3-100 \mathrm{mg}$ ) 
One of the major factors influencing the degree of the molecular iodine sorption from the gas flow is the time of contact between the composites and the gas flow. The time of the contact is determined by the linear gas flow rate and the height of the sorbent in the column. Figure 9 shows the data on the molecular iodine sorption from the gas flow as a function of the time of contact between the steam-air flow and the $\mathrm{SiO}_{2}-2 \% \mathrm{Ag}$ composite obtained by treatment of the precursor with a $2.0 \mathrm{M}$ ammonia solution. As follows from Fig. 9, when the time of the contact between gas phase and composite is decreased from 4.5 to $1.1 \mathrm{~s}$, the molecular iodine sorption remains virtually unchanged and is higher than $99 \%$. An increase the linear gas flow rate and hence, a decreases in the time of contact between the gas flow and the composite lowers the sorption front angle. Note that it takes two or three layers of the composite to localize radioactive iodine.

Another factor influencing the sorption efficiency is the composition of steam-air phase. The presence of water molecules in the gas phase has a competitive influence during the interaction of molecular iodine with active centers of the sorbent.

Figure 10 show the data on the molecular iodine sorption on the $\mathrm{SiO}_{2}-8 \% \mathrm{Ag}$ composite obtained by treatment of precursors with $0.1 \mathrm{M}$ solution of $\mathrm{HH}$ from steam-air flows with different steam quantities. As follows from Fig. 10, when the steam content in the gas phase is increased about twofold, the total degree of the molecular iodine sorption remains virtually unchanged and equal to more than $99 \%$. On the other hand, it is necessary note that an increase in the steam quantity in the gas phase causes the radioactive iodine to move along the column. Thus, even a small change in the steam quantity impacts the sorption capacity of the composites.

In conclusion note that all synthesized composites have high sorption efficiency for molecular iodine in the gas flow.

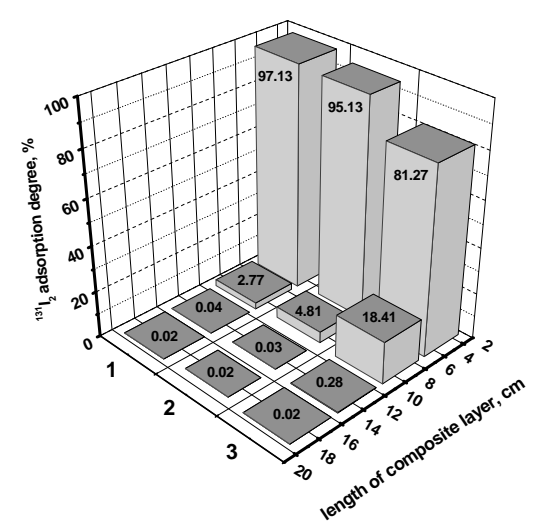

Fig. 9. The 131I layer-by-layer distribution on the column containing the $\mathrm{SiO}_{2}-2 \% \mathrm{Ag}$ composite material obtained by treatment of the precursor with $2.0 \mathrm{M}$ solution of $\mathrm{NH}_{4} \mathrm{OH}$ as a function of the time of contact between the steam-air flow and composite $(1-4.53 \mathrm{~s}, 2$ $2.06 \mathrm{~s}, 3-1.11 \mathrm{~s})$ 


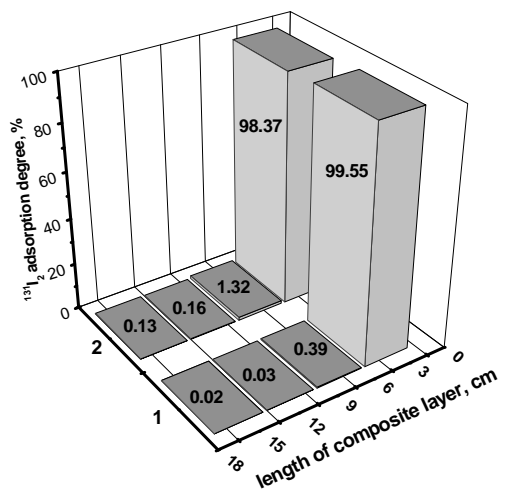

Fig. 10. The ${ }^{131} \mathrm{I}$ layer-by-layer distribution on the column containing the $\mathrm{SiO}_{2}-8 \% \mathrm{Ag}$ composite material obtained by treatment of the precursor with $0.1 \mathrm{M}$ solution of $\mathrm{HH}$ as a function of the steam quantity in the steam-air flow (1 - 5-6 vol\%, $2-10-11 \mathrm{vol} \%$ )

\subsubsection{A study of the $\mathrm{CH}_{3}{ }^{131}$ I sorption from the steam-air phase by the synthesized composites}

To study the localization of $\mathrm{CH}_{3}{ }^{131}$ I from a steam-air flow, we used the procedure and installation described in (Kulyukhin et al., 2007).

In contrast to the molecular iodine sorption, for which the sorption degree was higher than 99\% in all cases, the $\mathrm{CH}_{3}{ }^{131}$ I sorption efficiencies of the synthesized composites differ a lot. An increase in the $\mathrm{Ag}$ quantity increases the total $\mathrm{CH}_{3}{ }^{131}$ I localization degree. Thus, increasing the Ag quantity from 1 to $8 \mathrm{wt} \%$ for the composites prepared by treatment of the precursor with a $0.1 \mathrm{M}$ solution of $\mathrm{HH}$, the localization degree increases from $\sim 1.8 \%$ to $\sim 60.2 \%$ (Fig. 11A). An analogous picture is also observed for the composites obtained as a result of treatment of the precursors with solutions of HA or ammonia (Fig. 11B).

Analysis of the data on the total $\mathrm{CH}_{3}{ }^{131} \mathrm{I}$ sorption on the composites obtained by treatment with $0.1 \mathrm{M}$ solutions of $\mathrm{HH}$ and $\mathrm{HA}$, as well as with a $0.5 \mathrm{M}$ solutions of ammonia as a function of the Ag content in the material shows that increasing the Ag concentration in the material increases its sorption capacity. The highest $\mathrm{CH}_{3}{ }^{131}$ I sorption capacity of the composites is observed for the materials obtained by treatment of the precursors with a 0.1 $\mathrm{M}$ solution of HA, and the lowest sorption capacity is observed for the samples treated with a $0.5 \mathrm{M}$ solution of ammonia.

For the composites containing 1, 2 and $4 \mathrm{wt} \%$ of $\mathrm{Ag}$, the sorption capacity of the precursor is higher (Fig. 12A). For the composite containing $8 \mathrm{wt} \%$ of $\mathrm{Ag}$ the sorption efficiency of the material obtained by treatment of the precursor with a $0.1 \mathrm{M}$ solution of HA is higher than that of the precursor (Fig. 12B).

Note that for all composites containing 1,2, and $4 \mathrm{wt} . \%$ of $\mathrm{Ag}$, the quantity of the sorbed $\mathrm{CH}_{3}{ }^{131}$ increases from layer to layer (Fig. 13). The only exception are composites containing $8 \mathrm{wt} \%$ of $\mathrm{Ag}$, which display standard dependences; i.e., a decrease in the sorbed $\mathrm{CH}_{3}{ }^{131} \mathrm{I}$ along the column length (Fig. 13). The observed picture is likely to be due to a drop in the 
flow rate in the composite layer because of a rise in its turbulence, which leads to an increase in the time of contact between the gas phase and the composite.

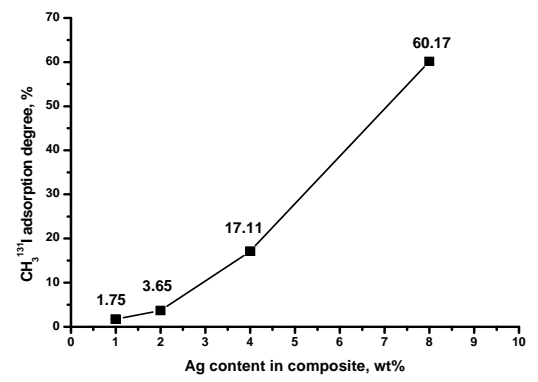

A

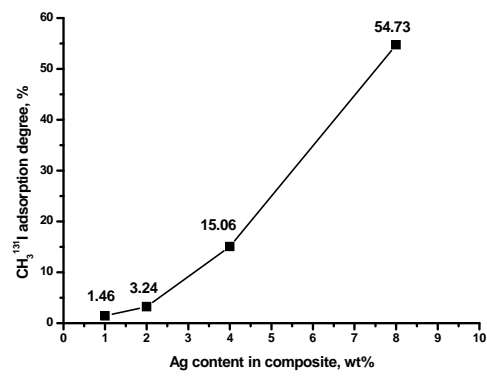

B

Fig. 11. The efficiency of $\mathrm{CH}_{3}{ }^{131}$ I sorption on the composite materials obtained by treatment of the precursor with a $0.1 \mathrm{M}$ solution of $\mathrm{HH}(\mathrm{A})$ and $0.5 \mathrm{M}$ solution of $\mathrm{NH}_{4} \mathrm{OH}$ (B) as a function of the Ag concentration in the material

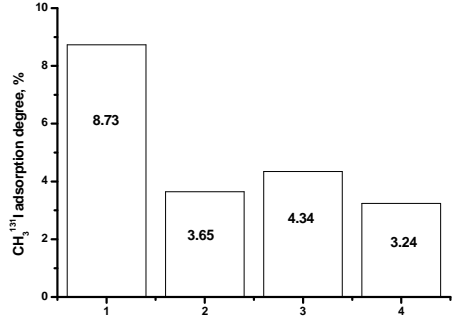

A

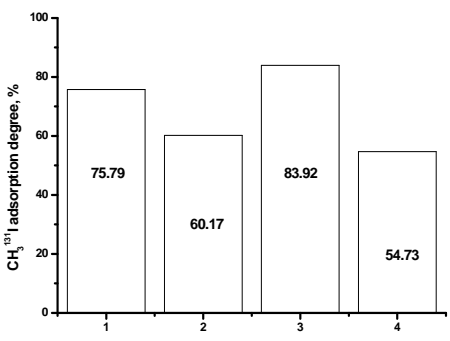

B

Fig. 12. The efficiency of the $\mathrm{CH}_{3}{ }^{131}$ I sorption on the $\mathrm{SiO}_{2}-2 \% \mathrm{Ag}(\mathrm{A})$ and $\mathrm{SiO}_{2}-8 \% \mathrm{Ag}$ (B) composite materials as a function of the nature of the $\mathrm{N}$-containing compound used for treatment of the precursor (1 - without the modification, 2 - $0.1 \mathrm{M} \mathrm{HH}, 3-0.1 \mathrm{M} \mathrm{HA}$, and 4 $0.5 \mathrm{M} \mathrm{NH}_{4} \mathrm{OH}$ )

The obtained data on the $\mathrm{CH}_{3}{ }^{131} \mathrm{I}$ sorption are very curious. $\mathrm{Ag}^{0}$ is known not to react with $\mathrm{CH}_{3}{ }^{131} \mathrm{I}$, whereas $\mathrm{Ag}_{2} \mathrm{O}$ can react with the compound in the presence of water steam by the reaction:

$$
2 \mathrm{CH}_{3}{ }^{131} \mathrm{I}+\mathrm{Ag}_{2} \mathrm{O}+\mathrm{H}_{2} \mathrm{O} \Rightarrow 2 \mathrm{Ag}^{131} \mathrm{I}+2 \mathrm{CH}_{3} \mathrm{OH} \text {. }
$$

Treatment of the precursors with $\mathrm{HH}$ and $\mathrm{HA}$ solutions leads to the formation of nanometer $\mathrm{Ag}^{0}$ particles in the material, and treatment with $\mathrm{NH}_{4} \mathrm{OH}$ yields nanometer $\mathrm{Ag}_{2} \mathrm{O}$ particles, which should suggest that the highest sorption efficiency for $\mathrm{CH}_{3}{ }^{131} \mathrm{I}$ would be characteristic of the composites obtained by treatment of the precursors with solutions $\mathrm{NH}_{4} \mathrm{OH}$. However in reality, the sorption efficiency of these composites proved to be the lowest. The nanometer $\mathrm{Ag}^{0}$ particles are likely to act as catalysts of the $\mathrm{CH}_{3}{ }^{131} \mathrm{I}$ decomposition into $\mathrm{CH}_{3}{ }^{\bullet}$ 
and ${ }^{131} 1^{\bullet}$ radicals. In this case, the $\mathrm{CH}_{3}{ }^{\bullet}$ can react with the components of the gas phase (oxygen and water steam) to form various volatile organic compounds. In turn, the $131 \mathrm{I}^{\bullet}$ can form ${ }^{131} I_{2}$ in the gas phase, which will be absorbed at a high speed by the silver compounds in the composition of the composites. The smaller the $\mathrm{Ag}^{0}$ particles are the higher their catalytic activity is.

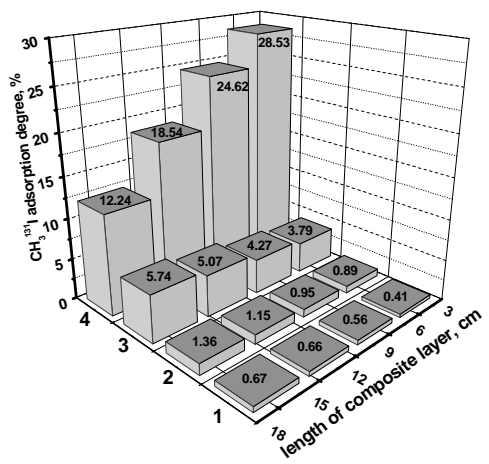

Fig. 13. The 131I layer-by-layer distribution on the column with the composite materials obtained by treatment of the precursor with a $0.1 \mathrm{M}$ solution of $\mathrm{HA}$ as a function of the $\mathrm{Ag}$ concentration in the material (1 - $1 \mathrm{wt} \% \mathrm{Ag}, 2$ - $2 \mathrm{wt} \% \mathrm{Ag}, 3-4 \mathrm{wt} \% \mathrm{Ag}, 4-8 \mathrm{wt} \% \mathrm{Ag}$ )

Increasing the concentration of the $\mathrm{HH}$ or $\mathrm{HA}$ should lead to both an increase in the quantity of nanometer $\mathrm{Ag}^{0}$ or $\mathrm{Ag}_{2} \mathrm{O}$ particles and their further aggregation. The aggregation will result in the formation of larger particles with a smaller specific surface. In this case, the catalytic activity of the composites should decrease, which can influence their sorption capacity.

Figure 14 shows the data on the total sorption degree for the synthesized composite materials as a function of the concentration of the N-containing compounds and used for treatment of the precursor. As was expected for the $\mathrm{SiO}_{2}-8 \% \mathrm{Ag}$ composite obtained by treatment of the precursor with solutions of $\mathrm{HH}$ and $\mathrm{HA}$, the sorption degree decreased with an increase in the concentration of the N-containing compound (Fig. 14A). On the other hand, the sorption degree of these materials is higher than that of the precursor. In the case of using $\mathrm{NH}_{4} \mathrm{OH}$ solutions, the sorption efficiency also decreases with an increase in the concentration of the $\mathrm{N}$-containing compound; however, it is not higher than the sorption capacity of the precursor (Fig. 14B).

Figure 15 shows the data on the ${ }^{131}$ I layer-by-layer distribution in the columns containing the $\mathrm{SiO}_{2}-8 \% \mathrm{Ag}$ composite obtained by treatment of the precursor with solutions of $\mathrm{N}$-containing compounds of different concentrations. Figure 15A shows that increasing the HA (or $\mathrm{HH}$ ) concentration leads to a noticeable decrease in the $\mathrm{CH}_{3}{ }^{131}$ I sorption in the 1st layer of the materials. Simultaneously, the angle of the sorption front becomes lower. In the case of $\mathrm{NH}_{4} \mathrm{OH}$ (Fig. 15B), 131I is virtually evenly distributed over the layers, and as in the case of $\mathrm{HH}$ and $\mathrm{HA}$, the highest sorption is observed for the lowest $\mathrm{NH}_{4} \mathrm{OH}$ concentration. Note that in the case of the composites obtained by treatment of the precursor with 1.0 and $2.0 \mathrm{M}$ solutions of $\mathrm{NH}_{4} \mathrm{OH}$, the sorption degree increases from layer to layer. The effect is again 
likely to be due to an increase in the turbulence of the gas flow as it passes through the column, which leads to an increase in the time of contact between the gas phase and the composite.

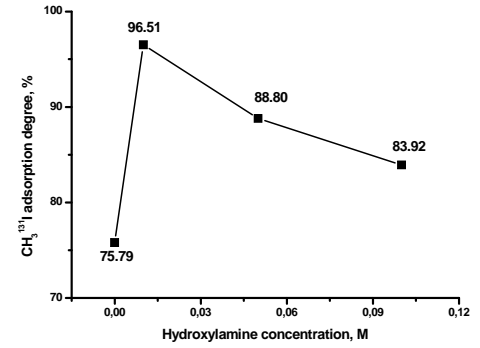

A

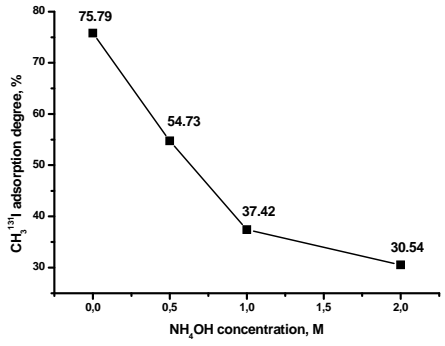

B

Fig. 14. The efficiency of the $\mathrm{CH}_{3}{ }^{131}$ I sorption on the $\mathrm{SiO}_{2}-8 \% \mathrm{Ag}$ composite, obtained by treatment of the precursor with a solution of $\mathrm{HA}(\mathrm{A})$ and $\mathrm{NH}_{4} \mathrm{OH}(\mathrm{B})$ as a function of the Ncontaining compounds concentration

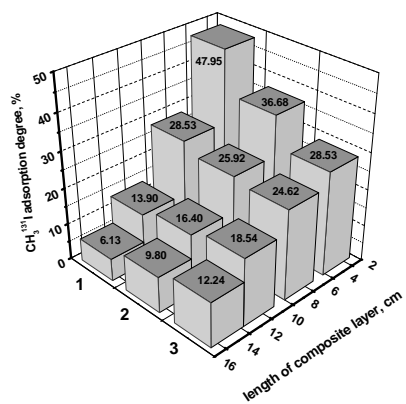

A

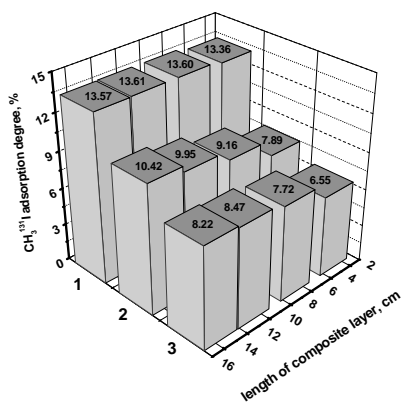

B

Fig. 15. The 131I layer-by-layer distribution on the column with the $\mathrm{SiO}_{2}-8 \% \mathrm{Ag}$ composite obtained by treatment of the precursor with a solution of HA (A, $1-0.01 \mathrm{M}, 2-0.05 \mathrm{M}, 3$ $0.1 \mathrm{M})$ and $\mathrm{NH}_{4} \mathrm{OH}(\mathrm{B}, 1-0.5 \mathrm{M}, 2-1.0 \mathrm{M}, 3-2.0 \mathrm{M})$ as a function of $\mathrm{N}$-containing compound concentration

As established earlier, the degree of the $\mathrm{CH}_{3}{ }^{131} \mathrm{I}$ and ${ }^{131} \mathrm{I}_{2}$ sorption depends on the quantity of radioactive compound supplied to the column.

Figure 16 shows the data on the $\mathrm{CH}_{3}{ }^{131}$ I sorption from the steam-air flow on the mixture (1:1) of composites $\mathrm{SiO}_{2}-8 \% \mathrm{Ag}$ obtained by treatment of the precursor with a $0.01 \mathrm{M}$ solution of $\mathrm{HH}$ and $\mathrm{HA}$ as a function of $\mathrm{CH}_{3}{ }^{131}$ I quantity. As follows from Fig. 16, a tenfold increase in the $\mathrm{CH}_{3}{ }^{131}$ I quantity leads to a decrease in its sorption degree from $99.3 \%$ to $95.6 \%$. On the other hand, increasing the $\mathrm{CH}_{3}{ }^{131}$ I quantity from 5 to $10 \mathrm{mg}$ has hardly any effect on the degree of its sorption on the composites. The 131I distribution in the layers changes accordingly. Increasing the $\mathrm{CH}_{3}{ }^{131} \mathrm{I}$ quantity lowers the angle of the sorption front. On the 
other hand, increasing the $\mathrm{CH}_{3}{ }^{131}$ I quantity from 5 to $10 \mathrm{mg}$ gives us virtually identical ${ }^{131} \mathrm{I}$ distribution patterns in the layers of the composites in the column.

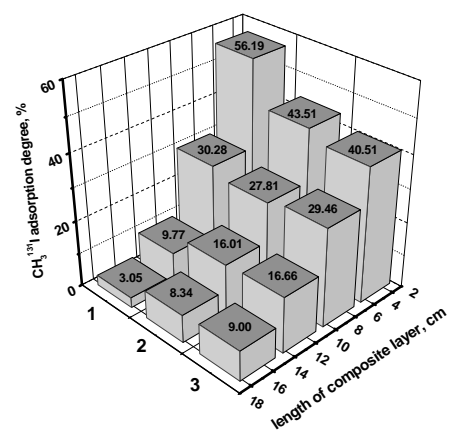

Fig. 16. The $\mathrm{CH}_{3}{ }^{131}$ I layer-by-layer distribution on the column with the mixture (1:1) of composites $\mathrm{SiO}_{2}-8 \% \mathrm{Ag}$ obtained by treatment of the precursor with a $0.01 \mathrm{M}$ solution of $\mathrm{HH}$ and $\mathrm{HA}$ as a function of $\mathrm{CH}_{3}{ }^{131} \mathrm{I}$ quantity supplied to the column ( $1-1 \mathrm{mg}, 2-5 \mathrm{mg}, 3-10$ $\mathrm{mg})$

The linear gas flow rate and the related time of contact between the gas phase and the composite also impact the sorption degree. Increasing the linear gas flow rate decreases the time of contact of $\mathrm{CH}_{3}{ }^{131} \mathrm{I}$ present in the gas phase with the elements of the composites responsible for its chemosorption (in the synthesized materials, these are nanometer $\mathrm{Ag}$ particles).

Figure 17 shows the data on the $\mathrm{CH}_{3}{ }^{131} \mathrm{I}$ sorption from the air flow on the composite $\mathrm{SiO}_{2}$ $8 \% \mathrm{Ag}$ obtained by treatment of the precursor with a $0.01 \mathrm{M}$ solution of HA as a function of the linear gas flow rate. A threefold increase in the linear gas flow rate decreases the

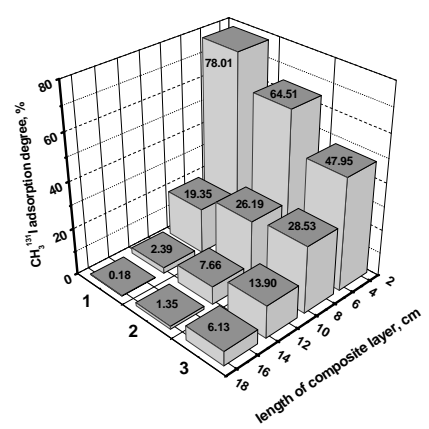

Fig. 17. The $\mathrm{CH}_{3}{ }^{131} \mathrm{I}$ sorption efficiency on the composite $\mathrm{SiO}_{2}-8 \% \mathrm{Ag}$ obtained by treatment of the precursor with a $0.01 \mathrm{M}$ solution of $\mathrm{HA}$ as a function of the linear gas flow rate $(1-4.4$ $\mathrm{cm} / \mathrm{s}, 2-8.1 \mathrm{~cm} / \mathrm{s}, 3-14.8 \mathrm{~cm} / \mathrm{s})$ 
sorption degree of $\mathrm{CH}_{3}{ }^{131}$ I from $99.9 \%$ to $96.5 \%$. The ${ }^{131} \mathrm{I}$ distribution in the layers of the composites in the columns also changed. As follows from Fig. 17, decreasing the linear gas flow rate increases the angle of the $\mathrm{CH}_{3}{ }^{131}$ I sorption front. Thus, increasing the linear gas flow rate from 4.4 to $14.8 \mathrm{~cm} / \mathrm{s}$ decreases the quantity of ${ }^{131}$ I in the $1^{\text {st }}$ layer of the composite in the column from $\sim 78$ to $\sim 48 \%$. At the same time, the ${ }^{131}$ I quantity in the $4^{\text {th }}$ layer increased from $\sim 0.2 \%$ to $\sim 6.1 \%$.

The findings of the investigations allow us to conclude that the most suitable composite material for $\mathrm{CH}_{3}{ }^{131} \mathrm{I}$ localization from the gas flow is $\mathrm{SiO}_{2}-8 \% \mathrm{Ag}$ obtained by treatment of the precursor with a $0.01 \mathrm{M}$ solution of HA.

\subsection{Composites, containing $\mathrm{Ag}, \mathrm{Ni}, \mathrm{Cu}$, and $\mathrm{Zn}$}

Presently, there is carrying out investigations aiming to produce a new granulated sorbent based on macroporous silica gel containing simultaneously nanometric particles of $\mathrm{Ag}$ and $\mathrm{Ni}$ (or $\mathrm{Zn}$, or/and $\mathrm{Cu}$ ) compounds for use in the filtering units of the emergency filters at WWER-1000 nuclear power plants (NPP-2006 project).

\subsubsection{Synthesis of composites}

The sorbents containing $10 \mathrm{wt} \%$ of $\mathrm{AgNO}_{3}$ and $\mathrm{Ni}\left(\mathrm{NO}_{3}\right)_{2}$ [or $\mathrm{Zn}\left(\mathrm{NO}_{3}\right)_{2}$, or/and $\mathrm{Cu}\left(\mathrm{NO}_{3}\right)_{2}$ ] were prepared by impregnation with an aqueous solution of d-element nitrates with the following treatment by ammonia with the following drying on air at increasing of temperature from 20 to $300^{\circ} \mathrm{C}$ and next air-conditioning at $300^{\circ} \mathrm{C}$.

Composites were synthesized in two stages:

1. Impregnation of macroporous silica gel with a solution of d-element nitrates in different ratio with the following drying on air at $110^{\circ} \mathrm{C}$;

2. Treatment of precursors with solutions of ammonia with the following drying on air at increasing of temperature from 20 to $300^{\circ} \mathrm{C}$ and next air-conditioning at $300^{\circ} \mathrm{C}$ during $4 \mathrm{~h}$.

The quantity of a solution of d-element nitrates, which is necessary for impregnation of silica gel, was taken in an amount ensuring 50\% filling of the volume of the silica gels. The volume of silica gel was calculated from its bulk weight, which equal $0.576 \mathrm{~kg} / \mathrm{m}^{3}$.

The quantity of d-elements nitrates for synthesis of composites was calculated on the basis of data about necessary d-element concentration in precursor.

The first stage of synthesis of precursors of composites on a basis of macroporous silica gel containing $\mathrm{Ag}$ and $\mathrm{Ni}$ (or $\mathrm{Zn}$, or/and $\mathrm{Cu}$ ) was carried out as follows. At intensive mixing a $434 \mathrm{~cm}^{3}$ of a solution of d-element nitrates with necessary concentration was added to $500 \mathrm{~g}$ of macroporous silica gel. The obtained mixture was mixed during $60 \mathrm{~min}$ for obtaining of uniformity of impregnation of total joint of silica gel with solution of d-element nitrates.

After obtaining of proportional impregnation of total joint of silica gel with solution of delement nitrates the wet sample was placed in BINDER drier. Precursors were dried on air at temperature $110^{\circ} \mathrm{C}$ to an air-dry state.

As a result of these operations there was a partial destruction of granules of precursor. Therefore before carrying out of the second stage of synthesis of composites it has been made the fractioning. As result of the fractioning of precursor granules with the size less than $1 \mathrm{~mm}$ has been separated. The quantity of the given fraction did not exceed 2-3\% from total synthesized joint of precursor.

As a result the precursors, containing $10 \mathrm{wt} \%$ of $\mathrm{Ag}$ and $\mathrm{Ni}$ (or $\mathrm{Zn}$, or/and $\mathrm{Cu}$ ), on the basis of macroporous silica gel were synthesized. 
At the second stage of synthesis of composites the precursors were treated by solution of $\mathrm{NH}_{4} \mathrm{OH}$ with the following drying on air at increasing of temperature from 20 to $300{ }^{\circ} \mathrm{C}$ and next air-conditioning at $300^{\circ} \mathrm{C}$ during $4 \mathrm{~h}$.

In our study $2.0 \mathrm{M}$ water solutions of ammonia were used for treatment of precursors.

The second stage consist on treatment of precursor by solution of $2.0 \mathrm{M}$ solution of $\mathrm{NH}_{4} \mathrm{OH}$ for obtaining of composites with nanometric particles of different compounds of d-element, was carried out as follows. At intensive mixing the $80 \mathrm{~cm}^{3}$ of $2.0 \mathrm{M}$ solution of $\mathrm{NH}_{4} \mathrm{OH}$ were added to $100 \mathrm{~g}$ air-dry precursor, containing $10 \mathrm{wt} \%$ of d-element nitrates. The obtained mixture was mixed during $60 \mathrm{~min}$ for obtaining of uniformity of impregnation of joint of precursor with solution of ammonia. During impregnation the colour of precursor changed from green to black for composites containing $\mathrm{Ag}$, $\mathrm{Ni}$ or/and $\mathrm{Cu}$, and from light grey to grey for composites containing Ag and Zn.

After obtaining of proportionality of impregnation of total joint of precursor that proved to be true of uniformity of colour, the wet samples were placed in exiccator on $3 \mathrm{~h}$. Through $3 \mathrm{~h}$ wet samples were placed in BINDER drier. The wet samples of composites were dried on air at increasing of temperature from 20 to $275-300^{\circ} \mathrm{C}$ with the following air-conditioning during $4 \mathrm{~h}$ at temperature $275-300^{\circ} \mathrm{C}$.

As a result of these operations the composites, containing $10 \mathrm{wt} \%$ of nanometric particles of different compounds of $\mathrm{Ag}$ and $\mathrm{Ni}$ (or $\mathrm{Zn}$, or/and $\mathrm{Cu}$ ), on a basis of macroporous silica gel were obtained (Table 1). The figure in the brackets shows the molar ratio of the metal.

\begin{tabular}{|c|c|c|c|c|}
\hline \multirow{2}{*}{ Composites } & \multicolumn{2}{|c|}{ Precursor } & \multicolumn{2}{c|}{ Composite } \\
\cline { 2 - 5 } & wet & dried & wet & dried \\
\hline $\mathrm{SiO}_{2}-10 \% \mathrm{AgNi}(1: 4)$ & green & light green & black & black \\
\hline $\mathrm{SiO}_{2}-10 \% \mathrm{AgCuNi}(1.6: 0.4: 4)$ & green & light green & black & black \\
\hline $\mathrm{SiO}_{2}-10 \% \mathrm{AgCuNi}(1: 1: 4)$ & green & light green & black & black \\
\hline $\mathrm{SiO}_{2}-10 \% \mathrm{AgCuNi}(0.4: 1.6: 4)$ & green & light green & black & black \\
\hline $\mathrm{SiO}_{2}-10 \% \mathrm{AgCu}(1: 4)$ & green & light green & black & black \\
\hline $\mathrm{SiO}_{2}-10 \% \mathrm{AgZn}(1: 4)$ & white & light grey & grey & grey \\
\hline
\end{tabular}

Table 1. The colour parameters of the synthesized composites

\subsubsection{Analysis of synthesized composites}

To determine the total metal content, the composite was treated with concentrated nitric acid for 2 hours. The mother solution was separated from it. The composite was washed with water, and the metal content was then determined. The Ag content in the solutions was measured by titration by the Volgard method. The nickel, copper and zinc contents were determined by direct titration with murexide (Schwarzenbach, 1958).

The amount of the metals in the form of nitrates in the composites was determined by the above methods in the solution which was obtained as a result of treatment of the composite with distilled water for 24 hours. The amount of d-elements in poorly soluble forms in the composite was calculated as the difference between the total concentrations of each metal in the composite and the amounts of the metals in nitrate form.

As a result, we obtained a granulated composites with a Ag content of $0.4 \div 2.0 \mathrm{wt} \%$ and a delement (Ni, Zn, Cu) content equal to its molar ratio to Ag from 14:1 to 4:1 (Table 1). 


\subsubsection{Electron microscopy study of synthesized composites}

Figure 18 shows the electron micrographs of the composite $\mathrm{SiO}_{2}-10 \% \mathrm{AgNi}(1: 4)$, obtained using a Philips TEM-301 transmission electron microscope. As shown in Fig. 18, the synthesized materials contain nanometer particles of $\mathrm{Ag}^{0}$ and possibly $\mathrm{NiO}$ not larger than $10 \mathrm{~nm}$. As follows from Fig. 18, the amount of nanometer $\mathrm{Ag}^{0}$ and $\mathrm{NiO}$ particles is very high. In addition, it is necessary to take into account a low concentration of Ag in the matrix of the composite with a strongly developed surface.

The Ag distribution in the matrix of the composites was studied using their electron probe X-ray microanalysis.

Figure 19 shows a typical microphotograph of the surface of the chip of the granule of the composite, and figure 20 shows the X-ray diffraction spectrum of the sample surface.

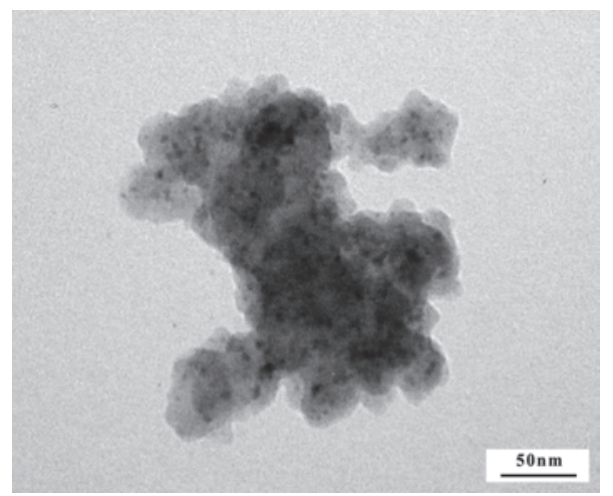

Fig. 18. The electron microphotograph of the $\mathrm{SiO}_{2}-10 \% \mathrm{AgNi}(1: 4)$ composite

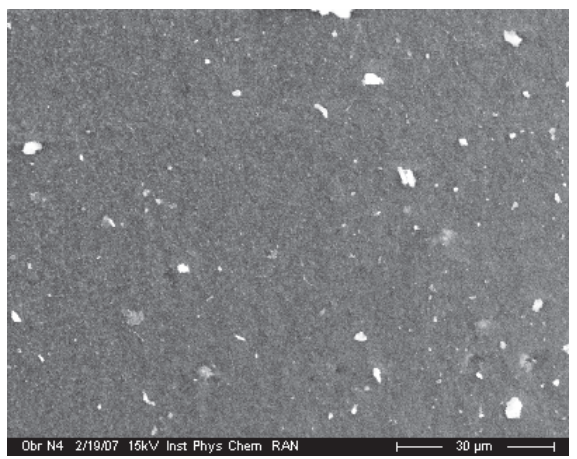

Fig. 19. The microphotograph of the surface of the $\mathrm{SiO}_{2}-10 \% \mathrm{AgNi}(1: 4)$ composite

As follows from Fig. 19, particles not larger than $1 \mu \mathrm{m}$ are evenly distributed on the granule surface and that the amount of the aggregates larger than $10 \mu \mathrm{m}$ is relatively small.

An elemental composition study of the surface showed that the composites contained $\mathrm{O}, \mathrm{Si}$, $\mathrm{Ni}, \mathrm{Ag}$ and trace quantity of $\mathrm{Na}$ (Fig. 20).

Figure 21 shows the X-ray spectroscopy data on the $\mathrm{Ag}(\mathrm{A})$ and $\mathrm{Ni}(\mathrm{B})$ distribution on the surface of granules of $\mathrm{SiO}_{2}-10 \% \mathrm{AgNi}(1: 4)$ composite. The surface of the granules was 
scanned separately at a radiation power characteristic of Ag or Ni. As follows from Fig. 21, the $\mathrm{Ag}$ and $\mathrm{Ni}$ are virtually evenly distributed on the surface of the composite granules.

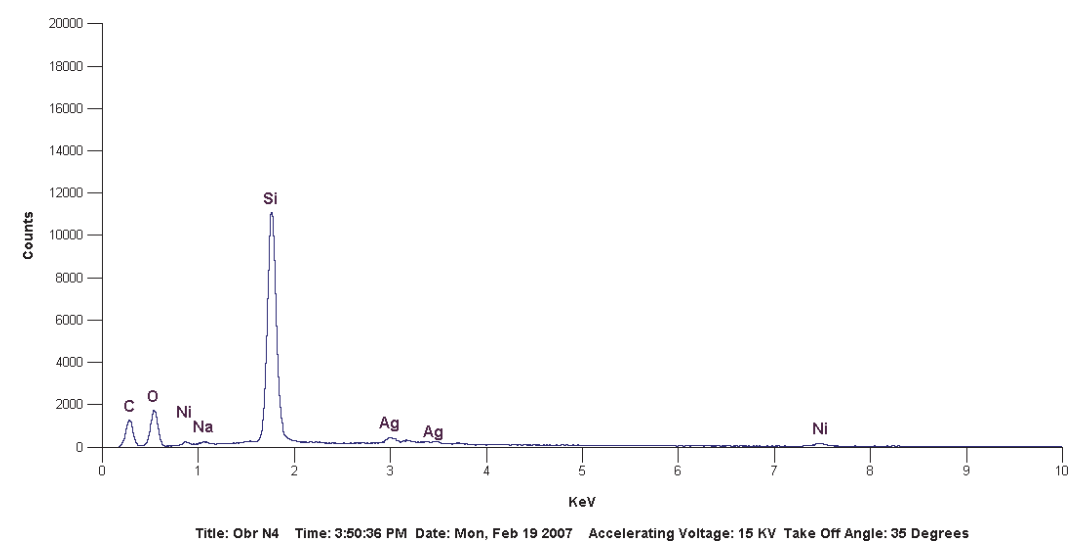

Fig. 20. The X-ray diffraction spectrum of the $\mathrm{SiO}_{2}-10 \% \mathrm{AgNi}(1: 4)$ composite

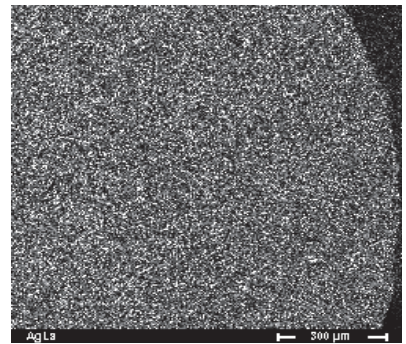

A

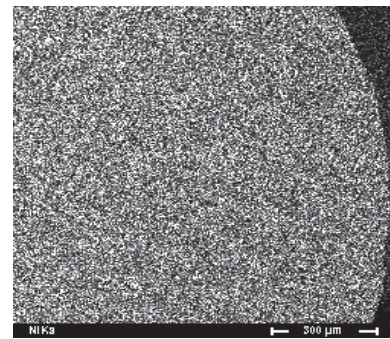

B

Fig. 21. The distribution of $\mathrm{Ag}(\mathrm{A})$ and $\mathrm{Ni}(\mathrm{B})$ particles on the surface of the granule of the $\mathrm{SiO}_{2}-10 \% \operatorname{AgNi}(1: 4)$ composite

\subsubsection{Thermal gravimetric analysis of synthesized composite}

The results of thermal gravimetric analysis of $\mathrm{SiO}_{2}-10 \% \mathrm{AgNi}(1: 4)$ and $\mathrm{SiO}_{2}-10 \% \mathrm{AgCu}(1: 4)$ composites are shown in Figs. 22-23. It can be seen that thermal decomposition of the composites is a multistep process accompanied by both evolution and absorption of heat.

As seen from Fig. 22, the patterns of thermal decomposition in air in a platinum crucible of $\mathrm{SiO}_{2}-10 \% \mathrm{AgNi}(1: 4)$ composite without conditioning during $4 \mathrm{~h}$ at $300^{\circ} \mathrm{C}$ and with it differ essentially. The composite obtained without conditioning during $4 \mathrm{~h}$ at $300^{\circ} \mathrm{C}$ (Fig. 22A) decomposes in two steps, the first of which is apparently associated with endothermic loss of water $\left(65-175^{\circ} \mathrm{C}\right)$. The second step is apparently related to partial exothermic decomposition of d-elements and ammonium nitrate $\left(265^{\circ} \mathrm{C}\right)$. The total loss of mass was about $30 \mathrm{wt} \%$. At the same time, as follows from Fig. 22B, the composite obtained with conditioning during $4 \mathrm{~h}$ at $300^{\circ} \mathrm{C}$ decomposes without thermal effects. The total loss of mass was about $11 \mathrm{wt} \%$. 
As follows from Fig. 23, the character of decomposition of $\mathrm{SiO}_{2}-10 \% \mathrm{AgCu}(1: 4)$ composite is similar to that for $\mathrm{SiO}_{2}-10 \% \mathrm{AgNi}(1: 4)$ composite. The $\mathrm{SiO}_{2}-10 \% \mathrm{AgCu}(1: 4)$ composite also decomposes without thermal effects. The total loss of mass was about $9 \mathrm{wt} \%$.

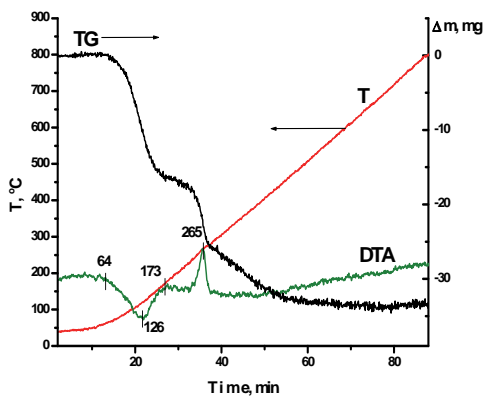

A

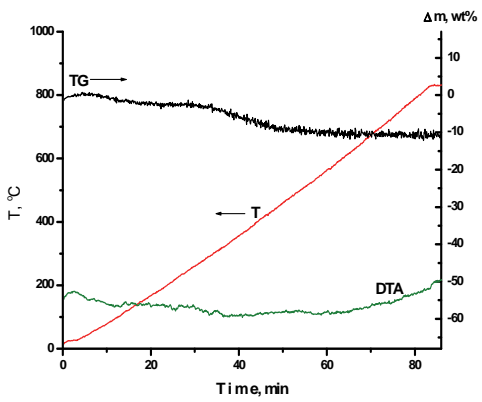

B

Fig. 22. Results of thermal gravimetric analysis of $\mathrm{SiO}_{2}-10 \% \mathrm{AgNi}(1: 4)$ composite without conditioning during $4 \mathrm{~h}$ at $300^{\circ} \mathrm{C}(\mathrm{A}$, sample weight $102.4 \mathrm{mg})$ and with it (B, sample weight $115.7 \mathrm{mg})$

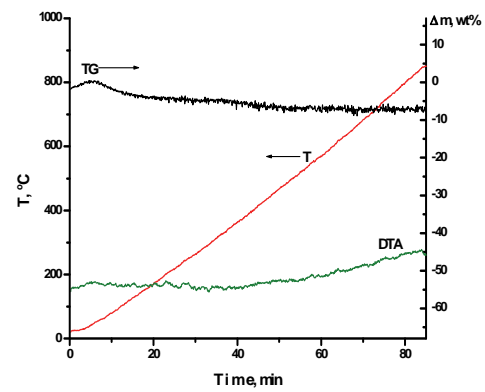

Fig. 23. Results of thermal gravimetric analysis of $\mathrm{SiO}_{2}-10 \% \mathrm{AgCu}(1: 4)$ composite (sample weight $89.9 \mathrm{mg}$ )

\subsubsection{Localization of molecular iodine and methyl iodide from a steam-air flow}

To study the localization of $\mathrm{CH}_{3}{ }^{131} \mathrm{I}$ and ${ }^{131} \mathrm{I}_{2}$ from a steam-air flow, we used the procedure and installation described in (Kulyukhin et al., 2007).

Results of the studies of the sorption of $\mathrm{CH}_{3}{ }^{131} \mathrm{I}$ and ${ }^{131} \mathrm{I}_{2}$ from a steam-air flow on developed composites are presented in Table 2. As follows from the Table 2, all composites have high sorption efficiency for $\mathrm{CH}_{3}{ }^{131} \mathrm{I}$ and ${ }^{131} \mathrm{I}_{2}$ in the gas flow. The highest $\mathrm{CH}_{3}{ }^{131}$ I sorption capacity is observed for the $\mathrm{SiO}_{2}-10 \mathrm{AgNi}(1: 4)$ composites, and the lowest sorption capacity is observed for the $\mathrm{SiO}_{2}-10 \mathrm{AgCuNi}(0.4: 1.6: 4)$ composites.

It is necessary note that with increasing of time of the contact between gas flow and composite the sorption efficiency appreciably increases. For example, at increasing of time 
of the contact between gas flow and $\mathrm{SiO}_{2}-10 \% \mathrm{AgNi}(1: 4)$ composite from 1 to $5 \mathrm{~s}$ the $\mathrm{CH}_{3}{ }^{131} \mathrm{I}$ adsorption degree increases from $88.74 \%$ to $99.99 \%$.

In conclusion note that synthesized composites containing $10 \mathrm{wt} \%$ of $\mathrm{Ag}$ and $\mathrm{Ni}$ have high sorption efficiency for ${ }^{131} \mathrm{I}_{2}$ and $\mathrm{CH}_{3}{ }^{131}$ I in the gas flow.

\section{Conclusion}

The developed composites do not have analogs in the world and can compete with other sorption materials designed to prevent the release of volatile radioiodine compounds into the environment. In addition, the developed composites can be used for effective localization of volatile chlorine, bromine, and arsenic, as well as polonium radionuclide into the environment.

\begin{tabular}{|c|c|c|c|c|}
\hline \multirow{2}{*}{ Composites } & ${ }^{131} \mathrm{I}_{2,} \%$ & \multicolumn{3}{|c|}{$\mathrm{CH}_{3}{ }^{131} \mathrm{I}, \%$} \\
\cline { 2 - 5 } & $20{ }^{\circ} \mathrm{C}$ & $20{ }^{\circ} \mathrm{C}$ & $110^{\circ} \mathrm{C}$ & $170^{\circ} \mathrm{C}$ \\
\hline $\mathrm{SiO}_{2}-10 \% \mathrm{AgNi}(1: 4)$ & 99.95 & 88.74 & 97.00 & 98.28 \\
\hline $\mathrm{SiO}_{2}-10 \% \mathrm{AgCuNi}(1.6: 0.4: 4)$ & 99.98 & 74.28 & 96.67 & 98.58 \\
\hline $\mathrm{SiO}_{2}-10 \% \mathrm{AgCuNi}(1: 1: 4)$ & 99.98 & 69.04 & 95.69 & 96.02 \\
\hline $\mathrm{SiO}_{2}-10 \% \mathrm{AgCuNi}(0.4: 1.6: 4)$ & 99.99 & 33.71 & 86.30 & 86.34 \\
\hline $\mathrm{SiO}_{2}-10 \% \mathrm{AgCu}(1: 4)$ & 99.99 & 64.89 & 95.38 & 97.15 \\
\hline $\mathrm{SiO}_{2}-10 \% \mathrm{AgZn}(1: 4)$ & 99.97 & 52.34 & 90.52 & 95.32 \\
\hline
\end{tabular}

Table 2. The sorption of ${ }^{131} \mathrm{I}_{2}(100 \mathrm{mg})$ and $\mathrm{CH}_{3}{ }^{131} \mathrm{I}(20 \mathrm{mg})$ from the air flow on the developed composites containing $10 \mathrm{wt} \%$ of d-elements (the surface area of the cross-section of the column $-3.3 \mathrm{~cm}^{2}$; the time of the experiment, including the time of the ${ }^{131} \mathrm{I}_{2} \mathrm{or}^{\mathrm{CH}_{3}{ }^{131} \mathrm{I}}$ supply - $4.0 \mathrm{~h}$; the composite particle size - 3.0-6.0 $\mathrm{mm}$, the linear steam-air flow speed in the column - 4-6 cm/s, the time of contact between gas phase and composite $-1 \mathrm{~s}$ ).

\section{Acknowledgment}

Authors thank Department of Chemistry and Material Science of Russian Academy of Sciences (program of fundamental research № 8 / academician A.Yu.Tsivadze/) for financial support.

\section{References}

Asmolov, V. G. (1994). Test data of severe accidents at WWER, Atomnaya Energiya (Russia), Vol.76, No.4, (April 1994), pp. 282-302, ISSN 0004-7163

Bronnikov, V. A. (2004). Eksperimentalnye Issledovaniya Protsessov Razrusheniya Aktivnoi Zony Reaktorov LWR Pri Tyazheloi Avarii (Proekt LACOMERA), Atomnaya Tekhnika za Rubezhom (Russia), No.11, (November 2004), pp. 16-20, ISSN 0320-9326

Bukrinskii, A. M. \& Fedulov, A. F. (1991). International scale of estimation of event risk at NPPs, Atomnaya Energiya (Russia), Vol.70, No.1, (January 1991), pp. 3-8, ISSN 00047163

Charlot, G. (1961). Les methods de la chimie analytique. Analyse quantitative minerale, Paris: Masson, 1961, 4th ed. Translated under the title: Metody analiticheskoi khimii. 
Kolichestvennyi analiz neorganicheskikh soedinenii, Vol.2, 1108, Khimiya, Moscow, Russia.

Containment Systems and Components for LOCA and Severe Accident Mitigation (1993). Promotion Materials from "Siemens AG. Power Generation Group (KWU)".

Dillman, y. G. \& Bunz H. (1991). Design of a Filter System for PWR Containment Venting, Journal of Aerosol Science, Vol.22, Supplement 1, pp. S701-S704, ISSN 0021-8502

Dragunov, Yu. G. \& Denisov, V. P. (2006). Support of safe operation of WWER unit at NPPs, Atomnaya Energiya (Russia), Vol.101, No.2, (August 2006), pp. 87-93, ISSN 0004-7163

Evans, G. J.; Melnyk, A. et al. (1990). The LIRIC database/model, Proceeding of $2^{\text {nd }}$ International Conference on Containment Design and Operation, 7.1-7.20, Toronto, Canada, October 1990.

Friesen, E.; Meseth J. et al. (2001). Containment behaviour in the event of core melt with gaseous and aerosol releases (CONGA), Nuclear Engineering and Design, Vol.209, No.1-3, (November 2001), pp. 253-262, ISSN 0029-5493

Kovalevich, O. (2000). What is preferentially: reconstruction or construction?, Journal of Russian Nuclear Society, No.1, (March 2000), pp. 34-38.

Krebs W.-D. (1999). The new generation, Siemens Power Journal, No.4, (April 1999), pp. 10-13

Kulyukhin, S. A.; Mizina, L. V. et al. (2007). Sorption of ${ }^{131} \mathrm{I}_{2}$ and $\mathrm{CH}_{3}{ }^{131}$ I from steam-air phase on porous inorganic sorbents containing d-elements, Radiokhimiya (Russia), Vol.49, No.2, (April 2007), pp. 156-158, ISSN 0033-8311

Kulyukhin, S. A.; Kamenskaya, A. N. et al. (2008). Chemistry of radioactive iodine in gas phase: fundamental and applied aspects, Radiokhimiya (Russia), Vol.50, No.1, (January 2008), pp. 3-21, ISSN 0033-8311

Kulyukhin, S. A.; Kamenskaya, A. N. \& Konovalova, N. A. (2011). Chemistry of radioactive iodine in aqueous phases: fundamental and applied aspects, Radiokhimiya (Russia), Vol.53, No.2, (April 2011), pp. 107-123, ISSN 0033-8311

Particulate Filtration in Nuclear Facilities (1991). Technical Report Series, No.241, 101, ISBN 92-0-125491-1, IAEA, Vienna, Austria.

Radioiodine Removal in Nuclear Facilities. Methods and Techniques for Normal and Emergencies Situations (1980). Technical Report Series, No.201, 98, ISBN 92-0-1252803, IAEA, Vienna, Austria.

Reactor Design (2002). Nuclear Engineering International, Advert. Supplement.

Rogers, J. T. (1990). Fission Product Transport Processes in Reactor Accidents, ISBN 9780891168768, Himespere Publishing, New York, USA.

Schwarzenbach, H. (1958). Complexometric titration, In: Complexonometry, N.I. Stupnikova, (Ed.), 104, Goskhimizdat, Moscow, Russia.

State of the art report on iodine chemistry (2007). Report NEA/CSNI. No.R1.

State of the art report on nuclear aerosols (2009). Report NEA/CSNI. No.R5.

State Standard 16187-70, Sorbents. A method of determination of fractional composition (1970). Committee of standards, measures and measuring devices at Ministerial council of the USSR, Moscow, Russia.

Tomorrow's reactors (2003). Alternatives, No. 2, (March 2003), pp. 4-5

Murata, T. \& Kamiya, K. (1968). Removal of iodine and methyl iodide by a full-sized charcoal filter, Proceedings of a symposium on operating and developmental experience in the treatment of airborne radioactive wastes, 451-463, New York, USA, August 26-30, 1968. 
Ustinov, O. A.; Sukhanov L.P. et al. (2005). Incidents at nuclear power plants, ways of their prevention and the localization of the incidents consequences, Russian Chemical Journal, Vol.49, No.4, (August 2005), pp. 54-60, ISSN 0373-0247

Zeyen, R. \& Clement, B. (2006). The PHEBUS Fission Product And Source Term International Programmes, Proceedings of Annual Meeting on Nuclear Technology "AMNT 2006", 234-239, Aachen, Germany, May 16-18, 2006. 


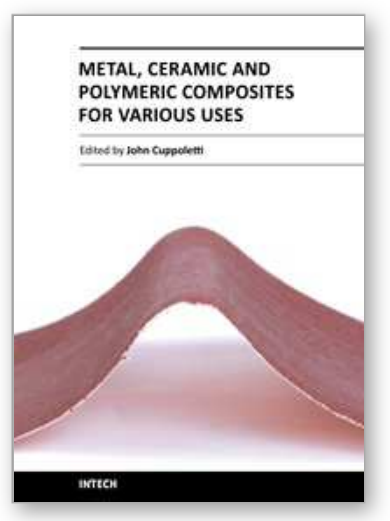

\author{
Metal, Ceramic and Polymeric Composites for Various Uses \\ Edited by Dr. John Cuppoletti
}

ISBN 978-953-307-353-8

Hard cover, 684 pages

Publisher InTech

Published online 20, July, 2011

Published in print edition July, 2011

Composite materials, often shortened to composites, are engineered or naturally occurring materials made from two or more constituent materials with significantly different physical or chemical properties which remain separate and distinct at the macroscopic or microscopic scale within the finished structure. The aim of this book is to provide comprehensive reference and text on composite materials and structures. This book will cover aspects of design, production, manufacturing, exploitation and maintenance of composite materials. The scope of the book covers scientific, technological and practical concepts concerning research, development and realization of composites.

\title{
How to reference
}

In order to correctly reference this scholarly work, feel free to copy and paste the following:

Sergey Kulyukhin, Lubov Mizina, Igor Rumer and Nikolai Mikheev (2011). The Composite Materials for Localization of Volatile Radioactive lodine Forms from Steam-Air Phase during Severe Accidents at NPPs, Metal, Ceramic and Polymeric Composites for Various Uses, Dr. John Cuppoletti (Ed.), ISBN: 978-953-307353-8, InTech, Available from: http://www.intechopen.com/books/metal-ceramic-and-polymeric-compositesfor-various-uses/the-composite-materials-for-localization-of-volatile-radioactive-iodine-forms-from-steam-airphase-d

\section{INTECH}

open science | open minds

\author{
InTech Europe \\ University Campus STeP Ri \\ Slavka Krautzeka 83/A \\ 51000 Rijeka, Croatia \\ Phone: +385 (51) 770447 \\ Fax: +385 (51) 686166 \\ www.intechopen.com
}

\author{
InTech China \\ Unit 405, Office Block, Hotel Equatorial Shanghai \\ No.65, Yan An Road (West), Shanghai, 200040, China \\ 中国上海市延安西路65号上海国际贵都大饭店办公楼 405 单元 \\ Phone: +86-21-62489820 \\ Fax: $+86-21-62489821$
}


(C) 2011 The Author(s). Licensee IntechOpen. This chapter is distributed under the terms of the Creative Commons Attribution-NonCommercialShareAlike-3.0 License, which permits use, distribution and reproduction for non-commercial purposes, provided the original is properly cited and derivative works building on this content are distributed under the same license. 